Information Technology Journal, 2010

ISSN 1812-5638

(C) 2010 Asian Network for Scientific Information

\title{
Research on Culture-Based Model of TV Home Shopping Development
}

\author{
'Lincong Yang and ${ }^{2}$ Yanqing Duan \\ 'School of Journalism and Communication, Hunan University, Hunan 410082, China \\ ${ }^{2}$ School of Business, University of Bedfordshire, Luton LU1 3JU, UK
}

\begin{abstract}
An empirical model based on five factors of consumer's cultural differences in TV home shopping is presented to predict the development of TV home shopping in this study. We have used the model to calculate the MOTHSD of 74 countries and regions. The results suggest that the higher MOTHSD of a country is, the faster development TV home shopping gets in the country. We have collected the data about TV home shopping in the three representative countries such as USA, UK and China to testify our model. The facts and practical figures are compatible with the results, which prove that the results got from the model are correct and our model is practical. The empirical model has the descriptive power on TV home shopping and our research can also provide a framework for management in electronic home shopping market.
\end{abstract}

Key words: Culture-based, empirical model, negative factor, positive factor, TV home shopping development

\section{INTRODUCTION}

TV home shopping, which began in the 1980s in America, is a fast growing industry and it is spreading to every TV screen across the earth. In developed countries and regions, TV home shopping has become a new fashion shop, hailed as the third revolution following the retail supermarkets (Cheng, 2006). In America TV home shopping sales accounted for the total volume of retail sales of $3.98 \%$ in 1993 and increased by $8 \%$ in 2008 . Online and TV shopping are the fastest growing sectors in UK (British Retail Consortium, 2009). The UK television home shopping is the market leadership in Europe and its market size is of 8.8 billion pounds, followed by Germany and 2004 television commercial revenues was of nearly 20 billion dollars. It developed very fast. Its sales accounted for the total volume of retail sales of $4.6 \%$ in 1996 and increased year on year by $14.3 \%$ in 2005 . UK retail market recorded sales is only $£ 265$ billion in 2008 which is $£ 15$ billion less than 2006, its TV home shopping sales increased by $£ 18$ billion which accounted for the total volume of retail sales of $22 \%$ in 2008 (Central Intelligence Agency, 2008). In 2008, China's entire total retail sales of consumer goods reached RMB 10.7 trillion, of which TV accounts for only RMB 20 billion, less than $0.19 \%$ of the total retail sales. Why does TV home shopping account for a big share in some country and a small share in other country? Why is it developing at such a big different ratio in these countries? Can we predict its development in a country to provide a framework for management in electronic home shopping market?
TV home shopping channels, one of the non-store based retailer formats, has received majority of research emphasis in the past few decades. Harden (1996), Eastlick and Liu (1997), Kim and Lennon (2000), Lee et al. (2005) and Lennon et al. (2003a) gained insight into consumers' attitudes and behavior as well as motivations towards television channels shopping. Feinberg and Eastlick (1995), De Long (1999) and Kwon and Lee (2003) probed into the perceived risks in the television home shopping. De Long (1999) and Greer and Kenner (1999) have determined a relationship exists between certain demographic characteristics such as gender, age, educational level and behavioral attentions when doing TV shopping. Product information on TV is an important aspect in the consumer purchase decision-making process. Wade and Mckechnie (1999) examined the likely impact of digital broadcasting on TV home shopping in UK. However, they pay little attention on consumers' cultural differences. Consumers' cultural differences play a very important role in the development of TV home shopping. Some impede the adopting TV home shopping and restrict its development, while others accelerate its adoption and its development. Therefore, an empirical model based on with five factors of consumer's cultural differences in TV home shopping is presented to predict the development of TV home shopping based in this study.

The study proceeds first by examining TV home shopping. The theoretical background to the research is then outlined. Next, it constructs an empirical model from the perspective of Hofstede model (Hofstede, 1980, 2003) and (Hofstede and Hofstede, 1991) of cultural dimensions

Corresponding Author: Lincong Yang, School of Journalism and Communication, Hunan University, No. 252,

Lushan South Road, Yuelu District, Changsha, 410082, China

Tel: 86-731-88821341 Fax: 86-731-88821341 
to predict the development of TV home shopping market and it can apply to TV home shopping market and electronic home shopping market. We do some evaluation of the Model of TV Home Shopping Development (MOTHSD). Conclusions are drawn and recommendations are proposed for further research.

\section{THEORETICAL BACKGROUND}

Culture is a complex, multifaceted construct. Culture is a like dropping an Alka-seltzer into a glass-you don't see it, but somehow it does something, in a word, Culture affects everything we do. The concept of culture and business has been extensively researched (Hofstede, 1980, 2003; Hofstede and Hofstede, 1991), both on how culture influences business practices, consumer choice and behavior (Hofstede and Hofstede, 1991; Hofstede, 2003; Hampden-Turner and Trompenaars, 1993, 1997). Cultural values have a significant effect on communication. They provide broad guidelines for acceptable ways of behaving and acting in particular situations (Feather, 1995). They influence how we interact and socialize with other members of society and affect the valences we attach to different situations (Feather, 1995) and are a powerful force shaping our motivations, lifestyles and product choices (Tse et al., 1989). In essence, cultural values represent the most basic and core beliefs of a society and these beliefs largely influence our communication patterns. Cultural differences are expected to pose influence on the consumers. It is inevitable that the cultural difference has impact on business. Understanding cultural differences is often considered a prerequisite for successful international communications. National cultures can be described according to the analysis of (Hofstede, 1980, 2003; Hofstede and Hofstede, 1991). His most basic five cultural dimensions are Power Distance Index (PDI), Individualism (IDV), Masculinity (MAS), Uncertainty Avoidance Index (UAI) and Long-Term Orientation (LTO).

- Power distance index focuses on the degree of equality, or inequality, between people in the country's society

- Individualism focuses on the degree the society reinforces individual or collective achievement and interpersonal relationships

- Masculinity focuses on the degree the society reinforces, or does not reinforce, the traditional masculine work role model of male achievement, control and power

- Uncertainty avoidance index focuses on the level of tolerance for uncertainty and ambiguity within the society-i.e., unstructured situations
- Long-term orientation focuses on the degree the society embraces, or does not embrace long-term devotion to traditional, forward thinking values

\section{EVALUATION MODEL OF TV HOME SHOPPING DEVELOPMENT}

Consumers' cultural differences play a very important role in the development of TV home shopping. Some cultural differences impede the adopting TV home shopping and restrict its development, while some accelerate its adoption and its development. In Hofstede cultural dimensions, there are five cultural differences (PDI, IDV, MAS, UAI and LTO) as described aforesaid. All these five factors have some impact on TV home shopping development. Power Distance and Individualism are two key factors influencing TV home shopping industry. Uncertainty avoidance and Long-term orientation also play an important role in its development. Masculinity plays a comparative small role. Based on these five cultural dimensions we develop a reference model which is called the Model of TV Home Shopping Development (MOTHSD) by synthesizing these factors that have influence on TV shopping development and the relationships among those factors.

Our reference model (MOTHSD) is presented as following:

$$
\begin{aligned}
\text { MOTHSD }= & \mathrm{C}_{1} \times\left(\text { MaxPDI }-\mathrm{D}_{\mathrm{PDI}}\right)+\mathrm{C}_{2} \times \mathrm{D}_{\mathrm{IDV}}+\mathrm{C}_{3} \times \mathrm{D}_{\text {MAS }} \\
& +\mathrm{C}_{4} \times\left(\text { MaxUAI }-\mathrm{D}_{\text {UAI }}\right)+\mathrm{C}_{5} \times\left(\text { MaxLTO }-\mathrm{D}_{\text {LTo }}\right)
\end{aligned}
$$

where, $\mathrm{D}_{\mathrm{PDI}}, \mathrm{D}_{\mathrm{IDV}}, \mathrm{D}_{\mathrm{MAS}}, \mathrm{D}_{\mathrm{UAI}}$ and $\mathrm{D}_{\mathrm{LTO}}$ the dimensions of PDI, IDV, MAS, UAI and LTO, respectively, $\mathrm{C}_{1}, \mathrm{C}_{2}, \mathrm{C}_{3}, \mathrm{C}_{4}$ and $\mathrm{C}_{5}$ present the weights of dimensions $\mathrm{C}_{1}, \mathrm{C}_{2}, \mathrm{C}_{3}, \mathrm{C}_{4}$ and $\mathrm{C}_{5}$, respectively and MaxPDI, MaxUAI and MaxLTO are the maximal values of $\mathrm{D}_{\mathrm{PDI}}, \mathrm{D}_{\mathrm{UAI}}$ and $\mathrm{D}_{\mathrm{LTP}}$, respectively. According to the scores of each cultural dimension in Hofstede cultural dimensions, MaxPDI, MaxUAI and MaxLTO are 104, 112 and 118, respectively.

In Hofstede cultural dimensions, the grouping of country scores points to some of the roots of cultural differences. Assumptions about historical roots of cultural differences always remain speculative but in the given examples they are quite plausible. In other cases they remain hidden in the course of history. Power distance is the most fundamental concept, because power and inequality, of course, are extremely fundamental facts of any society and all societies are unequal and some are more unequal than others. Of course it is also a key basic factor influencing TV home shopping industry. A High Power Distance ranking indicates that inequalities of power and wealth have been allowed to grow within the society. These societies are more likely to follow a caste 
system that does not allow significant upward mobility of its citizens. Centralization fostered large power distance. Large power distance fostered inequalities of power and wealth as well as a caste system in a society. The customer base of TV home shopping spans all socioeconomic groups, who share two common characteristics: cable subscription and above-average disposable income. So, large power distance reacts on TV home shopping negatively and $\mathrm{C}_{1}$ is a negative and has a bigger weight in our model. Individual or collective achievement and interpersonal relationships are also extremely fundamental issues, regarding all societies in the world. In business, individualist societies rely more heavily on facts and figures to determine the optimum outcome and ties between individuals are loose, personal freedom is valued and individual decision-making is encouraged. Many researchers found that isolated individuals who turn to television shopping networks are primarily for companionship. For example, Harden (1996) gained insight into women's attitudes towards television channels shopping and found that older women identified TV shopping as a form of entertainment and a way to alleviate loneliness and boredom. Lee et al. (2005) and Lennon et al. (2003b) found shoppers were motivated to shop on television due to parasocial interaction with the media hosts. Strong individualism reacts on TV home shopping positively and $\mathrm{C}_{2}$ is a positive and has a bigger weight in our model. Masculinity stands for a society in which social gender roles are clearly distinct: Men are supposed to be assertive, tough and focuses on material success; women are supposed to be more modest, tender and concerned with the quality of life. Femininity stands for a society in which social gender roles overlap: Both men and women are supposed to be modest, tender and concerned with the quality of life (Hofstede, 2001). The pattern of men and women's buying habits is determined primarily by underlying economic trends. However, women's combined earning power is still considerably lower than men's, as fewer women are working full time. In other markets except Internet shopping men still predominate as users (US Census Bureau, 2005). Strong masculinity plays a positive but comparative small role for TV home shopping and $\mathrm{C}_{3}$ is a positive but has a comparative small weight in our model. Uncertainty avoidance (Hofstede, 1980; Hampden-Turner and Trompenaars, 1993) focuses on the degree to which people in a country prefer structured over unstructured situations: from relatively flexible to extremely rigid. A high uncertainty avoidance ranking indicates the country has a low tolerance for uncertainty and ambiguity. This creates a rule-oriented society that institutes laws, rules, regulations and controls in order to reduce the amount of uncertainty and on the philosophical and religious level by a belief in absolute truth. People resist to making change, have low tolerance of deviant ideas and put greater emphasis on the tried and tested methods, are unlikely to take on high risks and are generally considered to be averse to ambiguity. So, strong uncertainty avoidance plays an important but negative role in TV home shopping and $\mathrm{C}_{4}$ is a negative and has the medium weight in our model. A high long-term orientation ranking indicates the country prescribes to the values of long-term commitments and respect for tradition, has a long term orientation and has thrift for investment. This is thought to support a strong work ethic where long-term rewards are expected as a result of today's hard work. Values associated with long term orientation are thrift and perseverance, an emphasis on the continuity of the past to the future, such as the adaptation of traditions to modern life and the perseverance towards slow gains. However, business may take longer to develop in this society, particularly for an outsider. Strong long-term orientation plays a negative role in TV home shopping and $\mathrm{C}_{5}$ is a negative and has a medium weight in our model.

From the above analysis we suggest the values of the weights of $\mathrm{C}_{1}, \mathrm{C}_{2}, \mathrm{C}_{3}, \mathrm{C}_{4}$ and $\mathrm{C}_{5}$ take $\mathrm{C}_{1}=1.1, \mathrm{C}_{2}=0.8$, $\mathrm{C}_{3}=0.1, \mathrm{C}_{4}=0.05$ and $\mathrm{C}_{5}=0.25$, respectively. Experiments show that the values of the weights are reasonable. By now, we have got our concrete model as follows:

$$
\begin{aligned}
\text { MOTHSD }= & 1.1 \times\left(104-\mathrm{D}_{\mathrm{PDI}}\right)+0.8 \times \mathrm{D}_{\mathrm{IDV}}+0.1 \times \mathrm{D}_{\text {MAS }} \\
& +0.05 \times\left(112-\mathrm{D}_{\text {UAI }}\right)+0.25 \times\left(118-\mathrm{D}_{\text {LTO }}\right)
\end{aligned}
$$

\section{EXPERIMENTAL RESULTS}

We use the data from Hofstede Cultural Dimensions to prove the efficiency of our model MOTHSD. These data are obtained from the editions of GH's work since 2001 , scores are listed for 74 countries and regions, partly based on replications and extensions of the IBM study on different international populations (Hofstede, 1980, 2003; Hofstede and Hofstede, 1991). We put these data into our MOTHSD (Eq. 2) and get their relevant results. However, of these scored countries and regions only 28 countries and regions are with the hofstede fifth dimension (LTO). So in the study, we only list the corresponding data and results of 14 , about a half, from these 28 countries and regions, which all have the fifth factor excluding France. We tested the proposed model MOTHSD on the chosen 14 countries and regions with the Hofstede five dimensions for each country. The original cultural dimensions of 14 chosen countries and regions are shown in Table 1. For more details about all the Hofstede scored 
Inform. Technol. J., 2010

Table 1: Original data of cultural dimensions of 14 chosen countries and regions

\begin{tabular}{|c|c|c|c|c|c|}
\hline Country & $\mathrm{D}_{\mathrm{PDI}}$ & $\mathrm{D}_{\mathrm{IDV}}$ & $\mathrm{D}_{\text {MAS }}$ & $\mathrm{D}_{\text {uAI }}$ & $D_{\text {Lто }}$ \\
\hline Australia & 36 & 90 & 61 & 51 & 31 \\
\hline Canada & 39 & 80 & 52 & 48 & 23 \\
\hline China & 80 & 20 & 66 & 30 & 118 \\
\hline France & 68 & 71 & 43 & 86 & 0 \\
\hline Germany & 35 & 67 & 66 & 65 & 31 \\
\hline Hong Kong & 68 & 25 & 57 & 29 & 96 \\
\hline India & 77 & 48 & 56 & 40 & 61 \\
\hline Japan & 54 & 46 & 95 & 92 & 80 \\
\hline Singapore & 74 & 20 & 48 & 8 & 48 \\
\hline South Korea & 60 & 18 & 39 & 85 & 75 \\
\hline Taiwan & 58 & 17 & 45 & 69 & 87 \\
\hline United Kingdom & 35 & 89 & 66 & 35 & 25 \\
\hline United States & 40 & 91 & 62 & 46 & 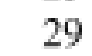 \\
\hline Vietnam & 70 & 20 & 40 & 30 & 8 \\
\hline
\end{tabular}

Table 2: MOTHSD of 14 chosen countries and regions

\begin{tabular}{lclc}
\hline Country & MOTHSD & Country & MOTHDSD \\
\hline United Kingdom & 180.800 & India & 91.550 \\
Australia & 177.700 & South Korea & 78.800 \\
United States & 174.950 & Taiwan & 78.600 \\
Canada & 167.650 & Singapore & 76.500 \\
Germany & 160.200 & Hong Kong & 74.950 \\
France & 138.600 & Vietnam & 71.000 \\
Japan & 111.800 & China & 53.100 \\
\hline
\end{tabular}

Table 3: TV home shopping sales (THSS) and total retail sales (TRS) in USA ( $\$$ millions), UK ( $£$ millions) and China (billion Yuan)

\begin{tabular}{|c|c|c|c|c|c|c|c|c|c|}
\hline \multirow[b]{2}{*}{ Years } & \multicolumn{3}{|l|}{ USA } & \multicolumn{3}{|l|}{ UK } & \multicolumn{3}{|l|}{ China } \\
\hline & TRS & THSS & THSS/TRS $(\%)$ & TRS & THSS & THSS/TRS $(\%)$ & TRS & THSS $(\%)$ & THSS/TRS \\
\hline 1993 & 447,451 & 17,754 & 3.97 & & & & & & \\
\hline 1994 & 479,684 & 20,120 & 4.19 & & & & & & \\
\hline 1995 & 501,768 & 21,636 & 4.31 & & & & & & \\
\hline 1996 & 530,289 & 24,808 & 4.68 & 167,679 & 7,640 & 4.6 & 2477 & 0.740 & 0.030 \\
\hline 1997 & 555,188 & 27,097 & 4.88 & 178,303 & 8,590 & 4.8 & 2725 & 0.100 & 0.003 \\
\hline 1998 & 586,995 & 30,538 & 5.20 & 186,591 & 10,150 & 5.4 & 2915 & 10.200 & 0.350 \\
\hline 1999 & 631,266 & 35,003 & 5.54 & 194,556 & 12.360 & 6.4 & 3114 & 20.000 & 0.640 \\
\hline 2000 & 673,616 & 42,759 & 6.35 & 207,784 & 15,410 & 7.4 & 3414 & 40.000 & 1.170 \\
\hline 2001 & 685,244 & 42,806 & 6.25 & 221,090 & 19,220 & 8.7 & 3759 & 6.000 & 0.150 \\
\hline 2002 & 714,809 & 48,639 & 6.80 & 234,546 & 22,340 & 9.5 & 4800 & 8.000 & 0.170 \\
\hline 2003 & 763,035 & 52,992 & 6.94 & 236,150 & 28.020 & 11.8 & 5331 & 4.584 & 0.080 \\
\hline 2004 & 837,750 & 59,937 & 7.15 & 246,922 & 32,060 & 13.0 & 5934 & 5.496 & 0.090 \\
\hline 2005 & 844,931 & 64,271 & 7.61 & 250,790 & 35,800 & 14.3 & 6700 & 7.300 & 0.110 \\
\hline 2006 & 898,624 & 75,230 & 8.37 & 280,885 & 40,096 & 14.2 & 7600 & $19.500^{*}$ & 0.250 \\
\hline 2007 & $4,500,000$ & 450,000 & 10.00 & 310,666 & 46,600 & 15.0 & 8900 & 10.500 & 0.120 \\
\hline 2008 & $4,478,300$ & 358,264 & 8.00 & 265,000 & 58,340 & 22.0 & 10700 & 20.000 & 0.190 \\
\hline
\end{tabular}

countries and their scores please see Hofstede Cultural dimensions (Hofstede, 2009). The corresponding simulated results are shown in Table 2 . However, Table 2 only listed the experimental results of the above 14 chosen countries and regions. To test the presented model more effectively, we also put the data of 74 countries and regions into our MOTHSD (Eq. 2) and get their relevant results, which are not shown in this study.

We have also collected the facts and practical figures of TV home shopping in the three representative countries such as UK, USA and China to testify our model. We can not collect all the data of TV home shopping in UK and USA; however, we choose the data of the electronic shopping in USA and multi-channel selling in UK which are now a common phenomenon across the retail world (British Retail Consortium, 2009; US Census Bureau, 2005; Research and Markets, 2001,
2003, 2005, 2008; RNCOS, 2007). The data of China come from Cheng (2006), Central Intelligence Agency (2008), Business Monitor International (2009) and Research in China (2008). The practical figures are shown in Table 3. We tested the proposed model MOTHSD with the data in Table 3. The experimental results from the model MOTHSD are consistent with the test data, which proves that the feasibility and effectiveness of our model.

\section{DISCUSSION}

From Table 2, it can be seen that the higher MOTHSD of a country is, the faster development TV home shopping gets in the country. We can see that United Kingdom and Australia as well as the United States have got the highest MOTHSD. Japan and South Korea have got the middle MOTHSD. Vietnam and China 


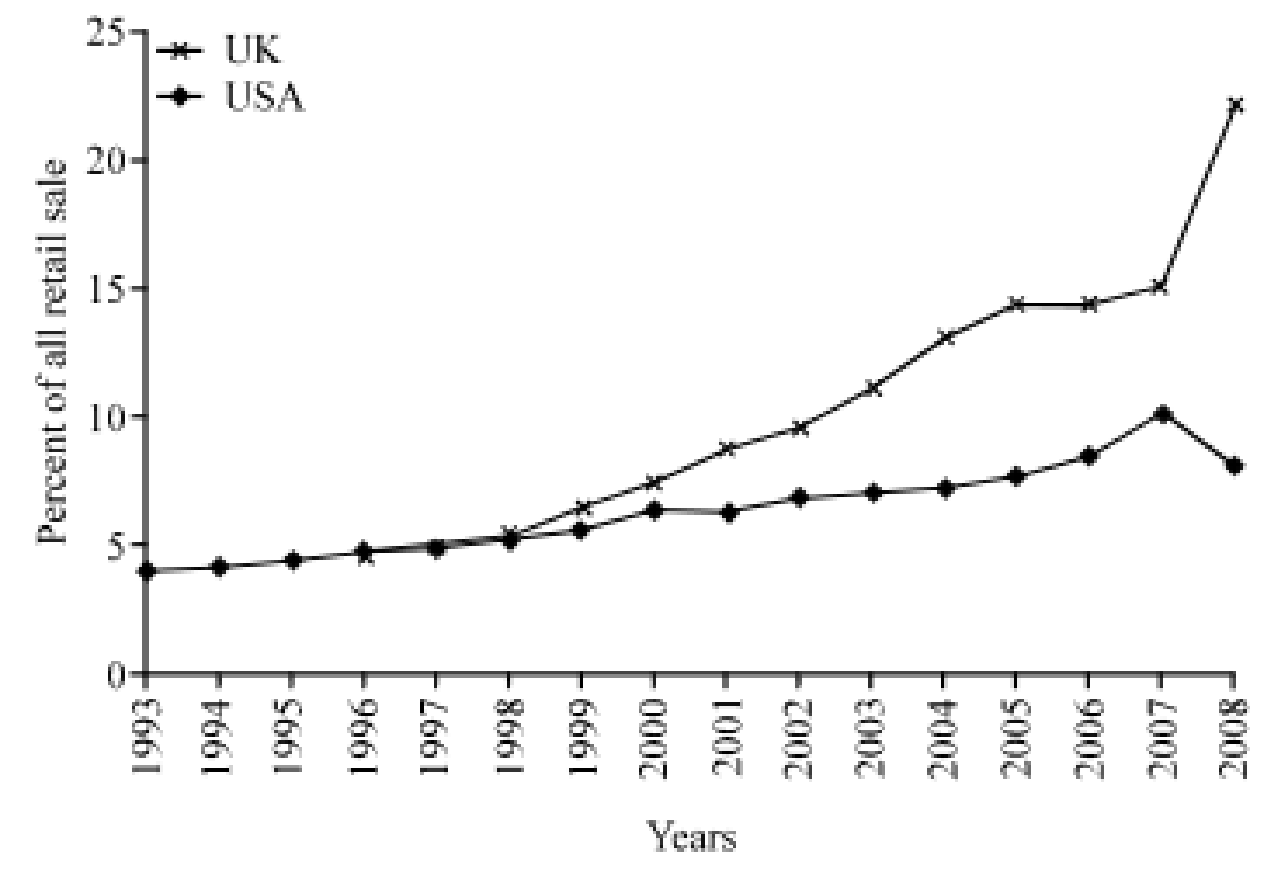

Fig. 1: UK and USA's TV home shopping development and its trends

have got the lowest HOTHSD. These data suggest that TV home shopping gets the fastest development in the USA and the UK; it develops quite fast in Japan and South Korea; but it gets the slowest development in China.

By observing Table 3, we can know that in America the TV home shopping sales accounted for the total volume of retail sales of $3.98 \%$ in 1993 and increased year on year by $8 \%$ in 2008 . In UK, the TV home shopping sales accounted for the total volume of retail sales of $4.6 \%$ in 1996 and increased year on year by $22 \%$ in 2008 . These data indicate that the TV home shopping sales in both USA and UK have increased fast and steadily and that the total markets in UK and USA have grown steadily. UK's TV home shopping gets the fastest and steady and mature development and their trends are promising and flourishing. The development and trends of TV home shopping in USA and UK are shown in Fig. 1.

However, the development of TV home shopping in China is very different. China's GDP was $\$ 7.33$ trillion in 2007 and increased by $\$ 7.99$ trillion in 2008, keeping ranking third in the world in 2007 and 2008. China Retail Industry has witnessed phenomenal growth in last few years. In 2008, total retail sales were RMB 10.7 trillion. It has increased with a more than tenfold increase rate since 2002, but TV home shopping just accounted for a very small share of the total retail sales with a very small increasing rate. From 2002 to 2008, it only accounted for $0.17,0.08,0.09,0.11,0.25,0.12$ and $0.19 \%$ share of the total retail sales, respectively. In 1997, it accounted for $0.003 \%$, the least share; then it increased by $1.17 \%$ in 2000 , the most share; but from then on it only accounted for about $0.1 \%$, with a small increasing rate since 2003 . These data suggest that its development was very unstable and immature and curved (Fig. 2). However, from Fig. 2 we can see that China TV home shopping has shown the sign of rising trend since 2008 and it will be

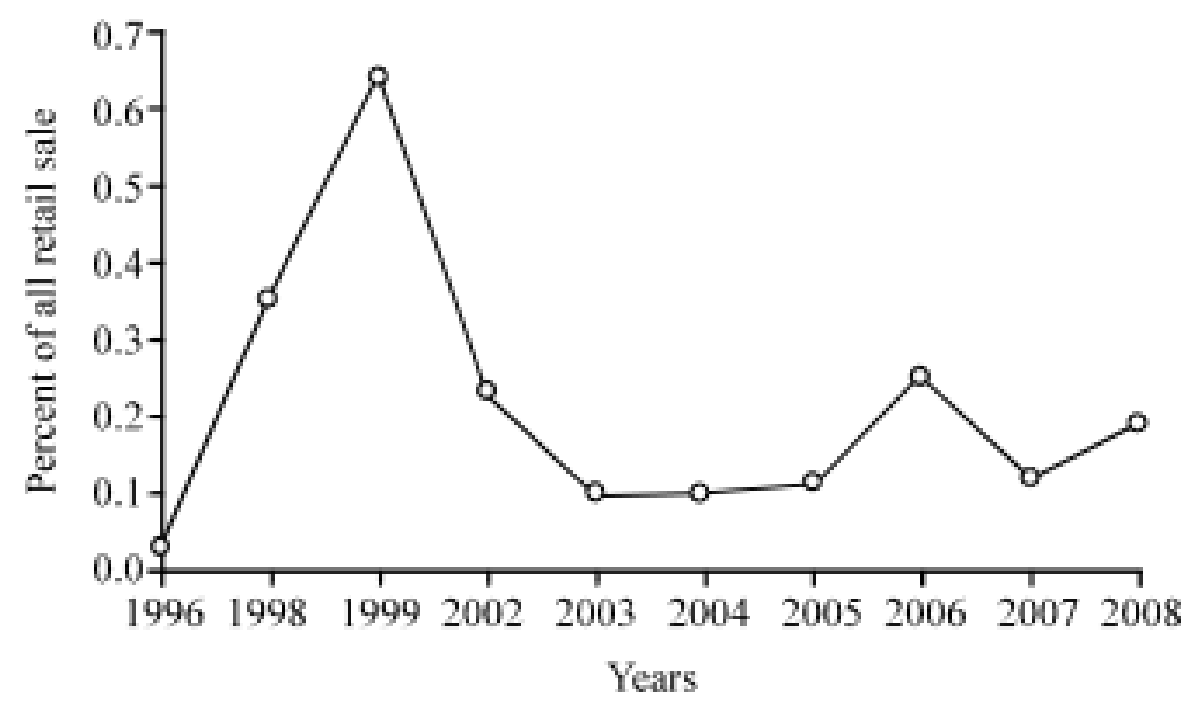

Fig. 2: China's TV home shopping development and its trend

likely to lead to a significant increase within the foreseeable future.

\section{CONCLUSION}

This study analyzes the impact of cultural differences on the development of TV home shopping. We have built a model (MOTHSD) with five factors of consumer's cultural differences in TV home shopping is developed to predict the development of the TV home shopping in this study. We have used the model to calculate the MOTHSD of 74 countries and regions. The results suggest that the higher MOTHSD of a country is, the faster development TV home shopping gets in the country. We have collected the data about TV home shopping in the three representative countries such as USA, UK and China to testify our model. The facts and practical figures are compatible with the results, which prove that our results are correct and our model is practical. However, we have only collected the data of the TV home shopping in USA, UK and China to examine our model and the comparison is only focused on these three countries. Our further work is to collect data from more countries to prove the correctness of our proposed model and perfect the model further.

\section{ACKNOWLEDGMENT}

This study is supported by The National Natural Science Foundation of China under grants 60736016 and 60973128 .

\section{REFERENCES}

British Retail Consortium, 2009. British retail consortium-latest data. http://www.brc.org.uk/ latestdatahome04.asp

Business Monitor International, 2009. China retail report Q4 2009: Market research report. Market Research.com. http://www.marketresearch.com/map/ prod/2422125.html 
Central Intelligence Agency, 2008. The World Factbook. CIA, China.

Cheng, H.X., 2006. Blocking or Reduced: TV Shopping Plans Health Road. Yangcheng Evening News, China.

De Long, J.B., 1999. Introduction to the symposium on business cycles. J. Econ. Perspect., 13: 19-22.

Eastlick, M.A. and M.M. Liu, 1997. The influence of store attitudes and other nonstore shopping patterns on patronage of television shopping programs. J. Direct Market., 11: 14-24.

Feather, N., 1995. Values, valences and choice: The influence of values on the perceived attractiveness and choice of alternatives. J. Personality Soc. Psychol., 68: 1135-1151.

Feinberg, R.A. and M.A. Eastlick, 1995. Direct marketing in the USA: Past failures and future promises. Int. J. Ret. Dist. Manage., 25: 256-261.

Greer, R.W. and J.O. Kenner, 1999. On-line shopping is changing the retail landscape. J. Family Consumer Sci., 91: 69-69.

Hampden-Turner, C. and F. Trompenaars, 1993. 7 Valuing Processes and the Dilemmas they Contain. Piatkus, The Seven Cultures of Capitalism London.

Hampden-Turner, C. and F. Trompenaars 1997. Response to geert hofstede. Int. J. Intercult. Relat., 21: 149-159.

Harden, A.J., 1996. TV shopping: A summary of women's attitudes gained through focus group discussions. J. Family Consumer Sci., 88: 58-62.

Hofstede, G., 1980. Culture's Consequences: International Differences in Work-Related Values. Sage Publications, Beverly Hills, London.

Hofstede, G. and G.J. Hofstede, 1991. Cultures and Organizations: Software of the Mind: Intercultural Cooperation and its Importance for Survival. McGraw-Hill, New York, pp: 3-19.

Hofstede G., 2001. Culture's Consequences. 2nd Edn., Sage, Beverly Hills.

Hofstede, G., 2003. Culture's Consequences, Comparing Values, Behaviors, Institutions and Organizations Across Nations. 2nd Edn., Sage Publications, Newbury Park, CA, USA.

Hofstede, Geert, 2009. Geert hofstede ${ }^{\mathrm{TM}}$ cultural dimensions. http://www.geert-hofstede.com/ hofstede_united_states.shtml

Kim, M. and S.J. Lennon, 2000. Television shopping for apparel in the United States: Effects of perceived amount of information on perceived risks and purchase intentions. Family Consumer Sci. Res. J., 28: 301-331.
Kwon, K. and J. Lee, 2003. Concerns about payment security of Internet purchases: A perspective on current on-line shoppers. Cloth. Text. Res. J., 21: 174-184.

Lee, H.H., A.M. Fiore and J.Y. Kim, 2005. The role of the technology acceptance model in explaining effects of image interactivity technology on consumer responses. Int. J. Ret. Dist. Manage., 34: 621-644.

Lennen, S.J., M.M. Sanik and N.F. Stanforth, 2003a. Motivations for Television shopping: clothing purchase frequency and personal characteristics. Cloth. Text. Res. J., 21: 63-74.

Lennon, M., I. Kirsch and M. von Davier, M. Wagner and K. Yamamoto, 2003b. Feasibility Study for the PISA ICT Literacy Assessment. ACER, Princeton, NJ, USA.

RNCOS, 2007. Blue April for UK Retail Industry as Sales Fell Unexpectedly. PRLog Free Press Release, UK.

Research and Markets, 2001. Home shopping market report. Key Note Publications Ltd, Jan. 2001. http://www.researchandmarkets.com/reportinfo.asp ?cat_id $=0$ \& report_id $=3702$.

Research and Markets, 2003. Home shopping market report. Key Note Publications Ltd., July 2003. http://www.researchandmarkets.com/reportinfo.asp ?cat_id $=0$ \&report_id $=35078$.

Research and Markets, 2005. Home shopping market report. Key Note Publications Ltd., Dec. 2005. http://www.researchandmarkets.com/reportinfo.asp ?report_id=461880.

Research and Markets, 2008. Home shopping market report. Key Note Publications Ltd., March 2008, pp: 97. http://www.researchandmarkets.com/reports/ 598512.

Research in China, 2008. China TV shopping market report, 2007-2008, 2008. Research in China. http:/www.researchinchina.com/htmls/Report/2008 /5598.html

Tse, D.K., R.W. Belk and N. Zhou, 1989. Becoming a consumer society: A longitudinal and cross-cultural content analysis of print ads from Hong Kong, The people's republic of China and Taiwan. J. Consumer Res., 15: 457-472.

US Census Bureau, 2005. Annual benchmark report for retail trade and food services: January 1992 through February 2005. Current Business Reports, Series BR/04-A, Washington, DC. http://www.census.gov/ $\operatorname{prod} / 2005$ pubs/br04-a.pdf

Wade, N. and S.A. Mckechnie, 1999. The impact of digital television: Will it change our shopping habits? J. Market. Commun., 5: 71-84. 